\section{International Scientific Journal Theoretical \& Applied Science}

p-ISSN: 2308-4944 (print) e-ISSN: 2409-0085 (online)

Year: 2017 Issue: 11 Volume: 55

Published: 20.11.2017 $\quad \underline{\text { http://T-Science.org }}$

A.S. Bondarenko MBA, Graduate student of Baltic State Technical University "Voenmeh"

D.F. Ustinov

modulmech@gmail.com

G.V. Kovalenko

Ph.D., Associate Professor of Peter the Great St.Petersburg Polytechnic University Gennady.Kovalenko@hse.spbstu.ru

SECTION 7. Mechanics and machine construction.

\title{
FEATURES OF DEVELOPMENT OF PRODUCTION OF SPORTS AND REHABILITATION EQUIPMENT IN RUSSIA -THE HISTORICAL ASPECT
}

\begin{abstract}
The history of the development of the simulator in Russia, namely the production of sports and rehabilitation simulators is an important area, the knowledge of which allows us to analyze and plan the development of promising areas for the development of simulator technologies. In existing studies on the history of the development of simulators in Russia, the patterns of simulator production on the basis of drive technology with a programmable load are not adequately described and revealed. The purpose of this work is a comparative analysis of the production of simulators in Russia and abroad in the period from the end of the 19th century to the present, taking into account these regularities.

In the work, a study is conducted of the features of the development of production facilities for the production of sports simulators in Russia. As a result, the proposed reasons for this development of production in Russia are formulated, the advantages and disadvantages of the Soviet system for the creation of sports simulators are revealed, and a classification of sports and rehabilitation simulators is suggested, taking into account the drive energy source.
\end{abstract}

Key words: history, production of simulators, sports and rehabilitation simulator, simulator based on drive technology with programmable load, electropneumatic drive.

Language: Russian

Citation: Bondarenko AS, Kovalenko GV (2017) FEATURES OF DEVELOPMENT OF PRODUCTION OF SPORTS AND REHABILITATION EQUIPMENT IN RUSSIA -THE HISTORICAL ASPECT. ISJ Theoretical \& Applied Science, 11 (55): 245-250.

Soi: http://s-o-i.org/1.1/TAS-11-55-32 Doi: crossef https://dx.doi.org/10.15863/TAS.2017.11.55.32

\section{ОСОБЕННОСТИ РАЗВИТИЯ ПРОИЗВОДСТВ СПОРТИВНЫХ И РЕАБИЛИТАЦИОННЫХ ТРЕНАЖЕРОВ В РОССИИ - ИСТОРИЧЕСКИЙ АСПЕКТ}

Аннотация: История развития тренажерного дела в России, а именно производства спортивньх и реабилитационных тренажеров является важной областью, знание которой позволяет анализировать и планировать разработку перспективных направлений развития тренажерных технологий. $B$ существующих работах по изучению истории развития тренажерного дела в России в недостаточной мере описань и выявлены закономерности производства тренажеров на базе приводной техники с программируемой нагрузкой. Целью данной работы является сравнительньй анализ производства тренажеров в России и за рубежом в период с конияа 19 века по настоящее время, учитьвающий указанные закономерности. Сформулированы предполагаемые причины сложившегося уровня развития производства в России, выявлены преимущества и недостатки советской системы по созданию спортивных и реабилитационных тренажеров.

Ключевые слова: история, производство тренажеров, спортивный и реабилитационный тренажер, тренажер на базе приводной техники с программируемой нагрузкой, электропневматический привод.

\section{Введение}

В России датой первого упоминания о тренажерах можно считать 10 августа 1885 года, когда в Санкт-Петербурге в квартире доктора
В.Ф. Краевского, собравшиеся решили создать первый в России Петербургский кружок любителей атлетики [1]. Особой популярностью у кружковцев, пользовалось поднимание 
тяжестей, хотя собрались борцы и гиревики, гимнасты и боксеры. В те же годы появляются книги с описанием различных, в том числе и силовых, упражнений, издаются атлетические журналы «Геркулес», «Красота и сила», «Русский спорт» и др. [2]. Краевский подал добрый пример, которому потом последовали в Москве, Риге, Царицыне, Киеве, Нижнем Новгороде, Ревеле и других городах, где также возникли атлетические кружки. И это не случайно. Если конный спорт или теннис на то время были доступны лишь очень богатым людям, то заниматься гантелями или гирями могли практически все. Но стоит отметить, что в популяризации такого спортивного направления как атлетика, использование силовых тренажеров особо не наблюдалось. Тренажеры больше использовались в лечебной практике.

\section{Материалы и методы}

В России в самом начале XX века стали открываться институты механотерапии и врачебной гимнастики, где использовались реабилитационные тренажеры, целью применения которых было восстановление работы суставов и мышц после травматических повреждений и лечения болезней обмена веществ посредством активно-пассивных упражнений. [3] Под руководством Семена Эйгорна в институте механотерапии и врачебной гимнастики в СанктПетербурге проводились сеансы врачебной гимнастики на тренажерах Густава Цандера, шведского физиотерапевта, основоположника механотерапии, изобретателя ряда аппаратов для лечебной гимнастики. В Цандеровских лечебницах с помощью механотерапии больные проходили реабилитационные процедуры. Для реализации точно направленной и строго дозированной нагрузки на отдельные органы, суставы и группы мышц шведским физиотерапевтом были сконструированы специальные аппараты-тренажёры, а для более глубокого лечебного воздействия на отдельные части тела - аппараты механического вибрационного массажа [4]. Спустя несколько лет помимо тренажеров Цандера стали использоваться механические конструкции, созданные для терапевтических целей другими изобретателями - М. Герцем, Г. Крукенбергом (Германия), Л. Бирковским (Польша), А. Габричевским (Россия). Эта плеяда талантливых изобретателей положила начало развитию восстановительных тренажеров, форму занятий с применением которых сейчас называют тренажерной гимнастикой (механотерапией или кинезотерапией).

В первые послереволюционные годы и в период гражданской войны институты, где практиковалась механотерапия, были закрыты.
Направление реабилитации в тренажерном деле по понятным причинам было фактически свернуто.

Окончание гражданской войны вызвало перестройку управления физической культурой. В стране были образованы Высший совет физической культуры и местные советы при исполкомах Советов рабочих и крестьянских депутатов. В 20-х и 30-х годах основной упор делался на участие профсоюзных организаций в физкультурной и спортивной работе. При них стали создаваться кружки (1923г.), в затем и коллективы физической культуры (1930г.). Упор делался на массовость.

Разворачивание массового физкультурного движения активизировало научноисследовательскую работу, которая в 30-х годах была в значительной мере нацелена на научное и методическое обоснование физических упражнений, повышение эффективности методов массовой физкультурно-спортивной работы, совершенствование спортивных тренировок. Большое внимание было уделено воздействию комплекса ГТО и отдельных видов спорта на занимающихся физической культурой, изучению влияния физических упражнений на повышение производительности труда. В этот период было создано несколько научно-исследовательских институтов, работающих в данном направлении (Москва, Ленинград, Харьков, Тбилиси [5]. В предвоенные годы занятия физической культура еще более активно использовались для военнопатриотического воспитания молодежи, повышения производительности труда и подготовке к защите Отечества. Основной упор делался на массовые состязания как фактор физического развития и военно-физической подготовки молодежи.

В 40-е годы интерес к лечебной физкультуре стал проявляться более значимо. Важным направлением работы физкультурных организаций стало восстановление здоровья в целях ускорение возвращения в строй раненных бойцов и командиров Советской Армии. Кроме того, физкультурные организации были нацелены на то, чтобы обеспечить госпитали страны кадрами специалистов по лечебной физической культуре и методическими работниками по использованию упражнений при различных видах ранений.

По окончании Великой Отечественной войны появилась возможность расширить подготовку и переподготовку кадров по физической культуре, поэтому 28 сентября 1945г. было принято постановление «Об оказании помощи комитетам по делам физической культуры и спорта и улучшении их работы». Была создана система подготовки и переподготовки кадров на курсах повышения 
квалификации работников по физической культуре и спорту различных органов государственного и общественного аппарата. Все это вызвало существенное увеличение выпуска спортивного инвентаря, формы и оборудования, в том числе тренажеров различного назначения.

В начале 60-х годов в СССР направление реабилитации получило новый импульс для своего развития. В 1958 году состоялось первое заседание Комитета экспертов Всемирной организации здравоохранения (BО3) по реабилитации, целью которого являлись предупреждение инвалидности в период лечения заболевания и помощь больному в достижении максимальной физической, психической, профессиональной, социальной и экономической полноценности, на которую он будет способен в рамках существующего заболевания. В 1960 году организационно было оформлено Международное общество по реабилитации инвалидов.

Одним из конкретных проявлений в 60-х годах нового подхода к физической культуре и спорту в нашей стране стало создание на предприятиях цехов здоровья. В их ведении находились спортивные сооружения, различные медико-профилактические службы и пр. [6]. В эти и последующие годы были сконструированы и изготовлены интересные по конструкции реабилитационные тренажеры для больных с опорно-двигательным аппаратом: аппарат профессора А.Минасяна для тренировки в ходьбе с дозированной нагрузкой, аппараты «подвесная дорога» для обучения ходьбе конструкции Штеренгерца, гимнастический тренажер Пустовойтенко, шарнирно-дистракционный аппарат Волкова-Оганесяна, апппарат Юрченко, блочный аппарат Красова для активной механотерапии, маятниковый тренажер Юлина, тренажер Агашина и другие [7].

К сожалению, на практике большее распространение получили, как правило, самые простые конструкции тренажеров. Они выпускались в СССР по нормативно-технической и конструкторской документации ВИСТИ (Научно-исследовательский институт спортивнотехнических изделий). Это организация ведет свое начало с 1936 года и по сей день, являясь в настоящее время единственной в России специализированной государственной научной организацией, аккредитованной Минобрнауки РФ по созданию спортивного оборудования, инвентаря, судейско-информационной аппаратуры и специальных приборов.

В пятнадцатилетний период времени, начиная с 1985 года в выпуске разных видов тренажеров участвовало около ста машиностроительных заводов. Так, например, велоэргометр «Здоровье» с нагрузочным устройством, приводной цепью, индикаторами движения (до 140 об/мин) и нагрузки (до 500 Вт), выпускался Херсонским комбайновым заводом Г.И.Петровского по чертежам ВИСТИ, тренировочное устройство «Педаль» изготавливался серийно Воронежским производственным объединением по выпуску экскаваторов имени Коминтерна, устройство «Горка» выпускался Днепропетровский экспериментальный завод спортметаллоизделий Центрального совета «Динамо» [1]. Данные тренажеры могли быть использованы не только для сугубо спортивного применения, но могли применяться и в быту [8].

Из серийно выпускавшихся тренажерных устройств, приспособлений и тренажеров к 1990му году в СССР были представлены:

1. «Универсал -1», «Универсал - 2» разработанные ВИСТИ и производимые на агрегатном заводе «Универсал» и Павловском машиностроительном заводе им. Мясникова [9];

2. «Гребля-Т-1», выпускающимися на опытном заводе «ОКБ «Теплоавтомат» (г. Харьков) устройство для имитации гребли. Развивает силу и выносливость с преимущественным воздействием на опорно-двигательный аппарат. Состоит из труб, подвижной банки, упоров для ног, весел и нагрузочного устройства.

3. Гимнастический комплекс «Здоровье» снаряд для развития скоростно-силовых возможностей организма с преимущественным воздействием на опорно-двигательный аппарат. Позволяет выполнять до 147 упражнений. Состоит из труб, подвижной тележки, эспандеров, рукоятки, платформы [10];

4. Гребной тренажер «Кавказец» - развивает силу и выносливость с преимущественным воздействием на опорно-двигательный аппарат. Портативное устройство из труб, имитирующее греблю на лодке. Нагрузочное устройство — пружины и резиновые амортизаторы;

5. Велотренажер «Роллер» - помогает развитию выносливости, оказывает преимущественное воздействие на сердечнососудистую и дыхательную системы. Состоит из рамы, педалей, цепной передачи, маховика, тормозного устройства [11];

6. Тренажер «Темп» - предназначен для общефизической подготовки, представляет собой конструкцию из труб, на которой расположены подвижное сиденье, нагрузочное устройство с рычагом и подставка для ног;

7. Тренажер «Горка» - рекомендуется для выполнения общеразвивающих упражнений. 
Работа на тренажере укрепляет мышцы плечевого пояса, спины, брюшного пресса, нижних конечностей, а также способствует развитию вестибулярного аппарата. Снаряд представляет собой конструкцию, состоящую из основания с амортизаторами, платформы с роликами, пружинами и ремнями;

8. Тренажер «Спектр» - предназначен для занятий по общефизической подготовке населения путем создания динамической нагрузки. Развивает основные группы мышц. Тип нагрузочного устройства фрикционный механизм и эспандеры Изделие может эксплуатироваться людьми любого возраста;

9. Тренажер «Беговая дорожка» - служит для имитации ходьбы и бега. Предназначен для общефизической подготовки населения в домашних условиях и в различных спортивных сооружениях;

10. Велотренажер «Педаль» - снаряд для развития выносливости, воздействует преимущественно на опорно-двигательный аппарат. Портативное устройство из труб и готовых деталей от велосипеда. Нагрузка собственный вес занимающегося;

11. Гимнастический снаряд «Машина здоровья Микулина» - укрепляет выносливость и силу, оказывает благотворное воздействие на опорно-двигательный аппарат. Состоит из двух деревянных стенок, соединенных трубчатыми перемычками, подвижней банки, фрикционного нагрузочного устройства, упоров для ног, рукоятки с сопротивлением [12];

12. Тренажер - массажер «Колибри» - имитация бега, массаж стоп ног и других частей тела;

13. Комплекс тросо-блочных тренажеров [13], [17], [18], [19], [20].

Рассматривая конструкции тренажеров и их функциональность, можно отметить, что в основном в СССР выпускались тренажеры с ручными/ножными механическими передачами: ремни, тросы, блоки, жгуты и пружины. С электрическим приводом выпускались только велотренажеры. Для сравнения - у зарубежных компаний в это время (в конце 80-х годов прошлого столетия) уже были протестированы и выпущены тренажеры на базе различных приводов: с электроприводом (фирма Tunturi), пневмоприводом (фирма Hur), гидроамортизаторами (фирма Kettler), магнитной системой нагружения (фирма Concept2) и другие. Хотя тренажеры с различными источниками энергии (тренажеры с гидравлическими, электрическими, пневматическими приводами и элементами), как и было ранее сказано, в СССР имели место быть. Так в работах авторов [14], [15] приводится описание специализированных тренажеров - прототипов в единичных экземплярах, изобретений отдельных научных работников ВНИИФК (Научноисследовательский институт физической культуры и спорта) и других организаций, инженеров, тренеров спортивных школ подготовки спортсменов высшей квалификации. Такие тренажеры были оснащены микропроцессорами с выходом на ЭВМ, для получения срочной обратной связи и контроля за ходом тренировки. Налаживание и отработка таких тренажеров не нашли свое отражение в серийном их производстве в СССР, а оставались для решения узкоспециализированных задач под каждый вид спорта.

История возникновения собственно российского тренажерного производства берет свое начало с крупных заводов по производству, ремонту авиационной техники, тракторов и другого промышленного оборудования, как это и было в советский период. Это закономерно, так как тренажеры выполняются из тех же материалов и сортамента для стальных конструкций и механизмов, на том же технологическом оборудование, что и детали, узлы, изготавливаемые на машиностроительных заводах. В начале 90-х годов, большинство этих заводов было закрыто, станочный парк был продан отдельным частным компаниям. Среди них были и компании по производству тренажеров, среди которых можно отметить такие компании как OOO «Пион», АO «Sport Line», OОО «НПП «Элмет», ООО «Феррум», OOO «MB Barell», OOO «В-Спорт», OOO «Iron King», ООО «Романа», ООО «ДК-Спорт», возникшие в период с 1991 по 1999 года. Стоит отметить, что на рынке тренажеров сегодня существуют фирмы, которые образовались еще в советский период, во второй половине 80-х годов. Например, кооператив «Сигма», ныне ООО «Сигма, которая в 1987 году выпускала на базе одного из тольяттинских подразделений ВАЗа спортивные тренажеры.

Средний возраст российских компаний, занимающихся выпуском тренажёров, по выборке из 20-ти ключевых игроков на этом рынке (первый эшелон) - порядка 22 года. Второй эшелон компаний - со средним возрастом порядка 13 лет (таких порядка 30 компаний). Общий средний возраст российских компаний порядка немногим менее 17-ти лет. Для сравнения с зарубежными компаниями, по году начала производства: фирма Kettler (Германия) 1949г., Body Sculpture (Великобритания) - 1965г., Tunturi (Финляндия) - 1922г., Technogym (Италия) - 1983г., Precor (США) - 1980г., Concept2 (США) - 1976г., Water Rower (США) - 
1987г. и так далее. Средний возраст компаний, 90\% тренажеров которых используются сегодня во многих фитнес-центрах и тренажерных залах в крупных городах России, составляет порядка 30 лет, что почти в два раза превышает возраст российских компаний.

На сегодняшний день в России существует более 50-ти фирм-компаний, производителей спортивного инвентаря и тренажеров. Среди них немногим более десятка компаний, производящих уличные тренажеры почти тридцать компаний производящих трособлочные, силовые тренажеры. Десяток компаний специализируются на производстве тренажеров для отдельных видов спорта, например, для хоккеистов - тренажер «ТМ Maxim hockey» (OOO «Урал-Сервис 95», г. Екатеринбург), тренажер для пловцов («ПТК «Спорт», Санкт-Петербург), для боксеров - подвески для мешков с электроприводом (ООО «Григорьев Компани», г. Димитров), тренажер «Лидер-А» для гребли на каноэ (автор тренажера Агапонов С.А.), тренажер для фигуристов (автор тренажера А. Мишин), тренажер с магнитно-жидкостной муфтой (разработчик ВИСТИ). Эти тренажеры, как правило, выпускаются в ограниченном количестве, часто в единичных экземплярах. Некоторые из вышеперечисленных компаний производят также и реабилитационные тренажеры. Как правило, это те же силовые, тросо-блочные тренажеры, только лишь с возможностью занятия на тренажерах инвалидов с колясками [16]. В целом, можно с уверенностью утверждать, что тренажеры для узкопрофильных задач в спорте и лечебной физической культуры, созданные в СССР, не нашли своего применения до сегодняшнего дня.

В настоящее время в спорте, лечебной физкультуре и фитнесе используются тренажеры различных мировых производителей в зависимости от используемого привода: трособлочные, ручные, с регулировкой нагрузки при помощи электродвигателей, гидроамортизаторов, электромагнитных маховиков и т.д. Однако, несмотря на исключительную важность качества нагрузки при восстановительном лечении или подготовки спортсмена, некоторым типам тренажеров в России крайне мало уделено внимания, включая вопросы их применения. В частности, это тренажеры с регулируемой нагрузкой на базе электропневмопривода, хотя они уже доказали свою состоятельность как при реабилитации людей с ограниченными возможностями, так и для обычных спортсменов.
[16] Производство сложных механических тренажеров на базе различных приводов (электрический, магнитный, пневматический) с программируемой нагрузкой практически отсутствует. Как было показано по ходу статьи, такое состояние дел в России с производством и применением таких тренажеров обусловлено объективными факторами:

- изначальной нацеленностью физкультурной системы для подготовки трудящихся СССР к обороне страны; отсутствием конкуренции и, соответственно, экономических стимулов к научно-техническому прогрессу в производстве тренажеров в СССР;

- наличием системы разрядов ГТО, которая вплоть до распада СССР предусматривала применение, как правило, простейших тренажерных снарядов: турников, брусьев и т.д.;

- потерей и остановкой развития, после распада СССР, множества теоретических и практических работ по проблемам спортивной тренировки с применением тренажеров;

- дешевизной изготовления тросо-блочных тренажеров и тренировочных приспособлений для непрофессионально-спортивного назначения, в том числе вследствие отсутствия требований к кинематике, динамике, энергетике движений.

Прекращение действия этих факторов, в том числе и инерционного характера, и усиливающееся внимание населения России как к нуждам соотечественников с ограниченными возможностями, так и собственному здоровью, дает отечественным производителям тренажеров c регулируемой нагрузкой шанс занять перспективную рыночную нишу реабилитации и поддержания здоровья в гораздо более широком социально-демографическом масштабе, чем это обеспечивают традиционные тросо-блочные тренажеры.

\section{Заключение}

Организация в России производства высокотехнологичных тренажеров с регулируемой нагрузкой, которые могут применяться различными социальнодемографическими и профессиональными группами населения для широкого спектра целей, особенно для реабилитации и поддержания здоровья, имеет высокие шансы на рыночный успех вследствие действия исторических, производственных и социально-экономических факторов. 


\begin{tabular}{l|lrl|l|ll} 
& ISRA (India) & $=\mathbf{1 . 3 4 4}$ & SIS (USA) & $=\mathbf{0 . 9 1 2}$ & ICV (Poland) & $=\mathbf{6 . 6 3 0}$ \\
Impact Factor: & ISI (Dubai, UAE) $=\mathbf{0 . 8 2 9}$ & PUHU (Russia) $=\mathbf{0 . 2 0 7}$ & PIF (India) & $=\mathbf{1 . 9 4 0}$ \\
& GIF (Australia) & $\mathbf{0 . 5 6 4}$ & ESJI (KZ) & $=\mathbf{3 . 8 6 0}$ & IBI (India) & $\mathbf{4 . 2 6 0}$
\end{tabular}

\section{References:}

1. Petrov V.K. (1991) Vash pomoschnik trenazher. - M.: Sovetskiy sport, 1991.- 46 p.

2. Vorobev A.N. , Sorokin Yu.K. (1987) Anatomiya silyi. - M.: Fizkultura i sport, 1987.$80 \mathrm{p}$.

3. (2001) Trenazhernyie sistemyi / V.E. Shukshunov. - M.: Mashinostroenie, 2001. $256 \mathrm{p}$.

4. Evseev, S.P. (2003) Trenazheryi v gimnastike / C.P. Evseev. - M.: Fizkultura i sport, 2003. $254 \mathrm{p}$.

5. Kukushkin V.V. Dobrov A.A. (1978) Vse o sporte. Spravochnik. Tom 2 - M.: Fizkultura i sport, 1978. - $220 \mathrm{p}$.

6. Pirogova L.A. (2008) «Osnovyi meditsinskoy reabilitatsii i nemedikamentoznoy terapii». Uchebnoe posobie L. A. Pirogova. - Grodno GrGMU, 2008. - 212 p.

7. Epifanov V.A. (1999) Lechebnaya fizicheskaya kultura i sportivnaya meditsina: Uchebnik. M.: Meditsina, 1999. - 304 p.

8. Yulin Yu.A. (1987) Trenazheryi - vashe zdorove. Sila, byistrota, vyinoslivost. Metod. rekomendatsii.- Dzerzhinsk: Upropoligrafizdat, 1987. -67 p.

9. Slutskiy M. (1989) Domashniy stadion. Trenazheryi na sluzhbe zdorovya. - M.: VDNH SSSR, 1989. - 28 p.

10. (1990) Trenazheryi v ozdorovitelnoy fizicheskoy trenirovke / Gluzman L.S., Cheban I.P., Klimenko S.I., Kozlova V.I. i dr. Kiev.: Vyischa shkola, 1990. - 158 p.

11. (1987) Kratkaya entsiklopediya domashnego hozyaystva / Pod red. I.M. Terehova. - M.: Sovetskaya entsiklopediya, 1987. - 639 p.
12. Deniskin D.N. (1986) Trenazheryi v dome, M.: Fizkultura i sport, 1986. $-26 \mathrm{p}$.

13. Barkov V.A., V.N.Starchenko V.N. (1993) Atletizm dlya vseh, Minsk.: Polyimya, 1993. $151 \mathrm{p}$.

14. Yushkevich T.P., Vasyuk V.E., Bulanova V.A. (1989) Trenazheryi v sporte. M.: Fizkultura i sport, 1989. -320 p.

15. Alabin V.G., Skripko A.D. (1979) Trenazheryi i trenirovochnyie ustroystva $\mathrm{v}$ fizicheskoy kulture i sporte: Spravochnik. - Minsk: Vyisshaya shkola, 1979.-176 p.

16. Kurdyibaylo S.F. (2014) Reabilitologiya. Tehnicheskie sredstva reabilitatsii invalidov $\mathrm{s}$ porazheniem oporno-dvigatelnoy sistemyi: ucheb.posobie. SPb.: Izd-vo Politehn.un-ta, 2014. - 316 p.

17. Ratov I.P. (1984) Ispolzovanie trenazherov dlya massovyih form fizicheskoy kulturyi. - M.: B.i., 1984. - 32 p.

18. Ratov I.P. (1985) Klassifikatsiya trenazherov i trenirovochnyih prisposobleniy dlya massovoy fizicheskoy kulturyi / I.P.Ratov, V.V. Ivanov, V.G. Usatyiy, P.I.Popov // teoriya i praktika fizichekoy kulturyi. -1985.-№11.-P.35-37

19. Ratov I.P. (1990) Kontseptsiya perspektivnogo razvitiya fizkulturno-sportivnyih trenazherov. // teoriya i praktika fizicheskoy kulturyi. - 1990. №8. - p.10-13.

20. Nesterov A.A., Dorofeev V.A.. Novoselov N.B. (1992) Trenazheryi v fizicheskoy podgotovke voinov. - M.: Voenizdat, 1992. 